\title{
Pontocerebellar hypoplasia type 10
}

INSERM

\section{Source}

INSERM. (1999). Orphanet: an online rare disease and orphan drug data base.

Pontocerebellar hypoplasia type 10. ORPHA:411493

Pontocerebellar hypoplasia type 10 is a rare, genetic, pontocerebellar hypoplasia subtype characterized by severe psychomotor developmental delay, progressive microcephaly, progressive spasticity, seizures, and brain abnormalities consisting of mild atrophy of the cerebellum, pons and corpus callosum and cortical atrophy with delayed myelination.

Patients may present dysmorphic facial features (high arched eyebrows, prominent eyes, long palpebral fissures and eyelashes, broad nasal root, and hypoplastic alae nasi) and an axonal sensorimotor neuropathy. 